\title{
Assessment of the Selected Heavy Metals Contamination of Fossil Fuel (Coal) within Okaba, Onyeama and Ribadu Mining Sites, Nigeria
}

Ademola Tokunbo Adetunji , Gbadebo Clement Adeyinka , Peter Amba Neji , Olaide Olawunmi Ajibola \& Babatunde Femi Bakare

To cite this article: Ademola Tokunbo Adetunji , Gbadebo Clement Adeyinka, Peter Amba Neji , Olaide Olawunmi Ajibola \& Babatunde Femi Bakare (2020): Assessment of the Selected Heavy Metals Contamination of Fossil Fuel (Coal) within Okaba, Onyeama and Ribadu Mining Sites, Nigeria, International Journal of Environmental Analytical Chemistry

To link to this article: https://doi.org/10.1080/03067319.2020.1807973

Published online: 25 Aug 2020.

Submit your article to this journal $\llbracket$

View related articles

View Crossmark data $\nearrow$ 


\title{
Assessment of the Selected Heavy Metals Contamination of Fossil Fuel (Coal) within Okaba, Onyeama and Ribadu Mining Sites, Nigeria
}

\author{
Ademola Tokunbo Adetunji (D) ${ }^{a}$, Gbadebo Clement Adeyinka (D) ${ }^{b}$, Peter Amba Nejic, \\ Olaide Olawunmi Ajibola (D) $^{\text {d,e }}$ and Babatunde Femi Bakare (D) ${ }^{\mathrm{b}}$
}

aDepartment of Pure and Applied Chemistry, Ladoke Akintola University of Technology, Ogbomoso, Nigeria; bDepartment of Chemical EngineeringMangosuthu University of Technology, Durban, South Africa; 'Department of Pure and Applied of Chemistry, University of Calabar, Calabar, Nigeria; ${ }^{\mathrm{d}}$ Faculty of Resource Science \& Technology, Universiti Malaysia Sarawak, Kota Samarahan; eInstitute of Biodiversity and Environmental Conservation, Unimas, Kota Samarahan

\begin{abstract}
Aim: The concentration levels of selected trace metals in coal samples collected from three different locations, namely Okaba coal deposit Kogi State, Onyeama coal deposit and Ribadu both in Enugu state, were investigated in this study.

Method: The representative coal samples were analysed for the presence of trace metals such as Cadmium, Chromium, Lead and Copper using an Atomic Absorption Spectrophotometer.

Result: The mean concentrations of $0.043 \pm 0.007,0.020 \pm 0.006$, $0.032 \pm 0.006$ and $7.245 \pm 0.557(\mathrm{mg} / \mathrm{kg})$ were observed for the selected metals. The concentration of the selected metals investigated with the exception of Lead was found to be above detection limit for EPA - NBS standard and compared to the previous work done globally. Conclusion: The emission of coal has been attributed to the release of critical heavy metals such as Cadmium, Chromium, Lead and Copper, into the environment thereby posing a threat to human health and endangering the ecosystem.
\end{abstract}

\section{ARTICLE HISTORY}

Received 23 June 2020

Accepted 28 July 2020

\section{KEYWORDS}

Coal; toxicity; heavy metals; Okaba; Onyeama; Ribadu

\section{INTRODUCTION}

Fuel may be defined as any substance capable of being ignited with the tendency of generating heat when combusted in air and obtainable in the large amount used for domestic purposes such as power generation, cooking, and heating [1].

They are products of natural processes of anaerobic decay of buried dead organisms and are carbonaceous materials. Organisms with their corresponding fossil take mostly over millions of years and in most cases exceed 650 million years [2]. The assumption that fossil fuels are products of fossilised remnants of dead plants [3] as a consequence of high temperature and pressure on biosphere over millions of years, thereby referred to as biogenic theory was first devised in 1556 by the duo George Agricola and Mikhail Lomonosov [4].

The utilisation of coal had been known for long in China before it was introduced to Europe. They were essentially utilised in North-Eastern China as a source of heat for 